\title{
Simultaneous Determination of Synthetic Phosphodiesterase-5 Inhibitors in Dietary Supplements by Liquid Chromatography-High Resolution/Mass Spectrometry
}

\author{
So-Hee Kim ${ }^{a \dagger}$, Ho Jun Kim ${ }^{a \dagger}$, Junghyun Son ${ }^{a \dagger}$, Byoung Wook Jeon ${ }^{a}$, Eun Sook Jeong ${ }^{\mathrm{b}}$, Eun Ju Cha ${ }^{\mathrm{a}}$, and \\ Jaeick Lee a $* \dagger^{\dagger}$ \\ ${ }^{a}$ Doping Control Center, Korea Institute of Science and Technology, Hwarangno 14-gil 5, Seongbuk-gu, Seoul, Korea \\ ${ }^{b}$ Department of Pharmacology and Pharmacogenomics Research Center, School of Medicine, Inje University, Pusan, Korea
}

Received May 29, 2012; Revised June 19, 2012; Accepted June 19, 2012

First published on the web June 28, 2012; DOI: 10.5478/MSL.2012.3.2.50

\begin{abstract}
After success of sildenafil for the treatment of erectile dysfunction, a large number of its analogues have been approved from FDA. Recently, the illegal dietary supplements which include sildenafil, vardenafil, tadalafil, or analogues of these drugs as ingredient have been widely distributed. Therefore, the determination of the residue of synthetic phosphodiesterase-5 (PDE-5) inhibitors in dietary supplements is highly required due to indiscriminate and unintentional overdose caused nausea, chest pains, fainting and irregular heartbeat. In this paper, we report a rapid and sensitive analytical method for the simultaneous determination of nine phosphodiesterase- 5 inhibitors by liquid chromatography-high resolution mass spectrometry. The present method was found to be accurate and reproducible with $40 \mu \mathrm{g} / \mathrm{g}$ of the limit of quantification for the nine PDE-5 inhibitors. The developed method can be successfully applied to the analysis of the seven illegal dietary supplements.
\end{abstract}

Key words: LC-HR/MS, LTQ-Orbitrap, Phosphodiesterase-5 inhibitor, Sildenafil

\section{Introduction}

The synthetic inhibitors of phosphodiesterase type 5 enzyme (PDE-5) including sildenafil, vardenafil and tadalafil, are generally prescribed for the treatment of erectile dysfunction (ED). Recently, many dietary supple- ments claimed for effective ED treatment are easily accessible via the internet market and daily consumption has intensely increased annually. There have been several reports for adulteration of dietary supplements containing one of those synthetic PDE-5 inhibitors at overdose ${ }^{1}$. The dietary supplements have been illegally spiked not only with sildenafil, vardenafil and tadalafil, but also analogues of these drugs. It is unsafe for patients to consume these analogues because of the lack of information regarding their safety and efficacy ${ }^{2}$. Hence it is important to deter- mine the synthetic PDE-5 inhibitors or those unknown analogues in dietary supplements.

Among the various techniques had been developed for the simultaneous determination of ED inhibitors and its analogues $^{3}$, liquid chromatography (LC) combined with tandem mass spectrometry (MS/MS) with selected reaction monitoring (SRM) mode has been widely used, because of its excellent sensitivity and selectivity ${ }^{4}$. Although SRM-based MS approach is useful for the determination of target

*Reprint requests to Dr. Jaeick Lee

E-mail: jaeicklee@kist.re.kr

These authors contributed equally to this work. molecules, the selective nature of SRM can conceal the other valuable information such as the presence of other (nontargeted) potential adulterants. Considering these points, high resolution/mass spectrometry seems to be the best candidate for simultaneous screening of both targeted and non-targeted analysis. The use of high resolving power-mass spectrometry, such as a linear ion trap coupled with an Orbitrap (LTQOrbitrap), might further improve the confidence in screening results obtained by full-scan accurate mass. The use of reconstructed ion chromatograms (RICs) with very narrow mass tolerance windows $(<10 \mathrm{ppm})$ is an efficient way to improve the selectivity and sensitivity of an LC-MS method ${ }^{5}$. However, the use of narrow mass tolerance windows is only feasible when the mass spectrometer provides sufficient resolving power to discriminate target molecules from isobaric co-eluting sample matrix compounds ${ }^{6}$. To our knowledge, no method has been developed to screen PDE-5 inhibitors in dietary supplements using liquid chromatography-highresolution/tandem mass spectrometry (LC-HR/MS).

In this paper, we report a rapid and sensitive analytical method for simultaneous screening of nine PDE-5 inhibitors using LC-HR/MS. This method applies to the determination of those substances in the illegal dietary supplements.

\section{Experimental}

Reagents
Standard references of sildenafil and its derivatives 
(vardenafil, homosildenafil, hongdenafil, hydroxyl homosildenafil, udenafil, pseudovardenafil, amino tadalafil, and tadalafil) including tablet of drugs were provided by Drug Analysis Center (Supreme Prosecutors' Office, Korea). The other four pellet-typed natural products (Schizandra \& balloon flower, pine needles, kelp and glasswort) were purchased from Pluslife (Seoul, Korea) (Table 3). Thionosildenafil as an internal standard (IS) was synthe- sized at Korea Institute of Science and Technology (Seoul, Korea). The structures of these drugs and IS, are shown in Figure 1. HPLC grade solvents (acetonitrile and methanol) were purchased from Burdick \& Jackson (Ulsan, Korea). Formic acid was obtained from Sigma (St. Louis, MO, USA). All other chemicals were analytical grade commercially available.

\section{Standard solutions and blank suspension}

Standard stock solutions at concentration of $1000 \mathrm{mg} / \mathrm{mL}$ were prepared by dissolving each nine standard references in methanol. The nine standard stock solutions were mixed and diluted with methanol at concentrations of 2, 5, 10, 50 and $100 \mu \mathrm{g} / \mathrm{mL}$ for the preparation of calibration samples. All stock solutions were stored at $4{ }^{\circ} \mathrm{C}$ and brought to room temperature just before use.

To prepare the blank suspension, $1000 \mathrm{mg}$ sample of each four kinds of natural supplements (pellet) were taken, mixed and ground into fine powders. $1000 \mathrm{mg}$ of sample powders was transferred to a volumetric flask $(100 \mathrm{~mL})$ and ultrasonically extracted with $100 \mathrm{~mL}$ methanol for $30 \mathrm{~min}$.

\section{Sample preparation}

Calibration samples at concentrations of 40, 100, 200, 1000 and $2000 \mu \mathrm{g} / \mathrm{g}$ powders were prepared by adding $0.2 \mathrm{~mL}$ of each calibration solution $(2,5,10,50$ and 100 $\mu \mathrm{g} / \mathrm{mL}$ ) to $1 \mathrm{~mL}$ of blank suspension ( $10 \mathrm{mg}$ powders $/ \mathrm{mL})$. Quality control samples used in the validation study at concentrations of 40,200 and $1,000 \mu \mathrm{g} / \mathrm{g}$ were prepared by the same way. $400 \mu \mathrm{L}$ of IS solution $(0.5 \mathrm{mg} / \mathrm{mL}$ in acetonitrile) was added to $100 \mu \mathrm{L}$ of calibration samples or

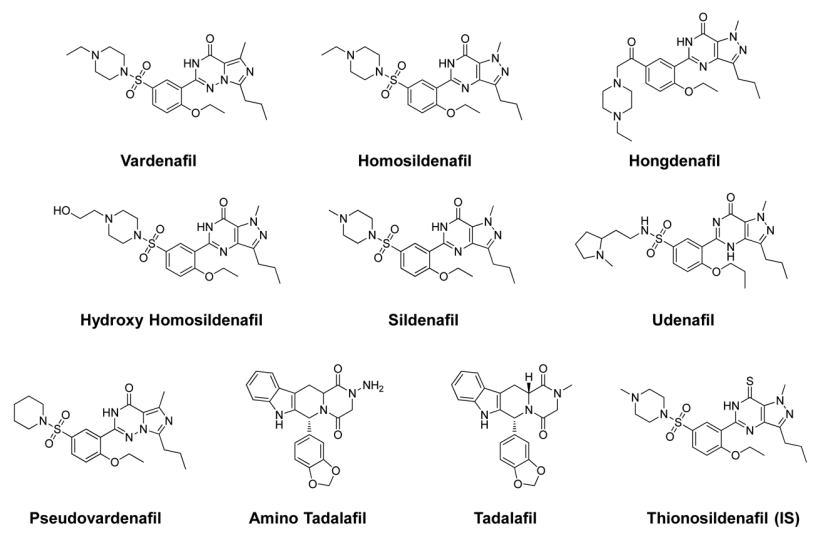

Figure 1. Chemical structures of nine PDE-5 inhibitors and internal standard. quality control samples. After mixing and centrifugation, the supernatants was filtered through a $0.45 \mu \mathrm{m}$ membrane filter and directly injected into the LC-HR/MS.

\section{Instruments}

Analysis of the drugs was performed on a Finnigan LTQ Orbitrap mass spectrometer (Thermo Fisher Scientific, San Jose, USA) equipped with a binary pump system (Thermo Fisher Scientific, San Jose, USA). The analytical column was a reversed-phase $\mathrm{C}_{18}(100 \mathrm{~mm} \times 2.1 \mathrm{~mm}$ i.d., $5 \mathrm{~mm}$, Neston, UK). The mobile phase consisted of (A) water with $0.1 \%$ formic acid and (B) acetonitrile with $0.1 \%$ formic acid. A linear gradient was employed from 20 to $95 \%$ (B) for $6 \mathrm{~min}$ with a flow rate of $0.3 \mathrm{~mL} / \mathrm{min}$. Column temperature was maintained at $30{ }^{\circ} \mathrm{C}$ using a column oven controlled by thermostat.

Electrospray ionization (ESI) was performed in the positive mode with nitrogen as sheath gas, sweep gas and auxiliary gas with the optimum values set at 40, 5, and 20 (arbitrary units). The capillary temperature was set at $320{ }^{\circ} \mathrm{C}$ and ESI spray voltage was adjusted to $5 \mathrm{KV}$. The mass spectrometer was operated at a resolution of 30,000 . The full scan was acquired in centroids mode for each target molecules in the range of $\mathrm{m} / \mathrm{z} 380$ to 530 . The data acquisition was controlled by Xcalibur 2.0 software.

\section{Validation study \\ Linearity and calibration curve}

The calibration curves for sildenafil and its derivatives were generated by plotting the peak area ratio of standard to the IS versus the concentrations of reference in the calibration range by least-square linear regression. The dynamic ranges constructed from 40 to $2000 \mu \mathrm{g} / \mathrm{g}$ for all reference standards.

\section{Accuracy and precision}

Quality control samples at concentrations of 40, 200 and $1000 \mu \mathrm{g} / \mathrm{g}(\mathrm{n}=3)$ were prepared and assayed to determine the accuracy and precision of an analytical method. The accuracy and precision were determined using intra-day and inter-day (3 days) data. The lower limit of quantification (LOQ) was determined as the lowest concentration on the standard calibration curve which was measured with an accuracy of between $80 \%$ and $120 \%$ and a precision of less than $20 \%$.

\section{Results and Discussion}

\section{Selectivity}

This method was developed for the simultaneous determination of sildenafil and its derivatives in natural dietary supplements using a high resolution mass spectrometry with a positive-ESI mode. All nine analytes produced the protonated molecule $[\mathrm{M}+\mathrm{H}]^{+}$that could be detected as base peak ions ranging $\mathrm{m} / \mathrm{z} 391.14008$ to 517.25915 (Table 1). Thionosildenafil (IS) was used as an internal standard and its protonated molecules could be detected as base peak 
Table 1. Names and compositions of nine standard references

\begin{tabular}{ccc}
\hline \hline Compound & Composition & {$[\mathrm{M}+\mathrm{H}]^{+}$} \\
\hline Vardenafil & $\mathrm{C}_{23} \mathrm{H}_{32} \mathrm{~N}_{6} \mathrm{O}_{4} \mathrm{~S}$ & 489.22785 \\
Homosildenafil & $\mathrm{C}_{23} \mathrm{H}_{32} \mathrm{~N}_{6} \mathrm{O}_{4} \mathrm{~S}$ & 489.22785 \\
Hongdenafil & $\mathrm{C}_{25} \mathrm{H}_{34} \mathrm{~N}_{6} \mathrm{O}_{3}$ & 467.27652 \\
Hydroxy Homosildenafil & $\mathrm{C}_{23} \mathrm{H}_{32} \mathrm{~N}_{6} \mathrm{O}_{5} \mathrm{~S}$ & 505.22277 \\
Sildenafil & $\mathrm{C}_{22} \mathrm{H}_{30} \mathrm{~N}_{6} \mathrm{O}_{4} \mathrm{~S}$ & 475.21220 \\
Udenafil & $\mathrm{C}_{25} \mathrm{H}_{36} \mathrm{~N}_{6} \mathrm{O}_{4} \mathrm{~S}$ & 517.25915 \\
Pseudovardenafil & $\mathrm{C}_{22} \mathrm{H}_{29} \mathrm{~N}_{5} \mathrm{O}_{4} \mathrm{~S}$ & 460.20130 \\
Amino Tadalafil & $\mathrm{C}_{21} \mathrm{H}_{18} \mathrm{~N}_{4} \mathrm{O}_{4}$ & 391.14008 \\
Tadalafil & $\mathrm{C}_{22} \mathrm{H}_{19} \mathrm{~N}_{3} \mathrm{O}_{4}$ & 390.14483 \\
\hline
\end{tabular}

ions. Therefore, a full scan mode was performed in the range of $\mathrm{m} / \mathrm{z} 380-530$ with positive-ESI mode for all the target molecules including IS. Not only the present method is useful for observing the presence of both target and nontargeted compounds but also it has incredibly low level of background noise compared to SRM-based MS approach.
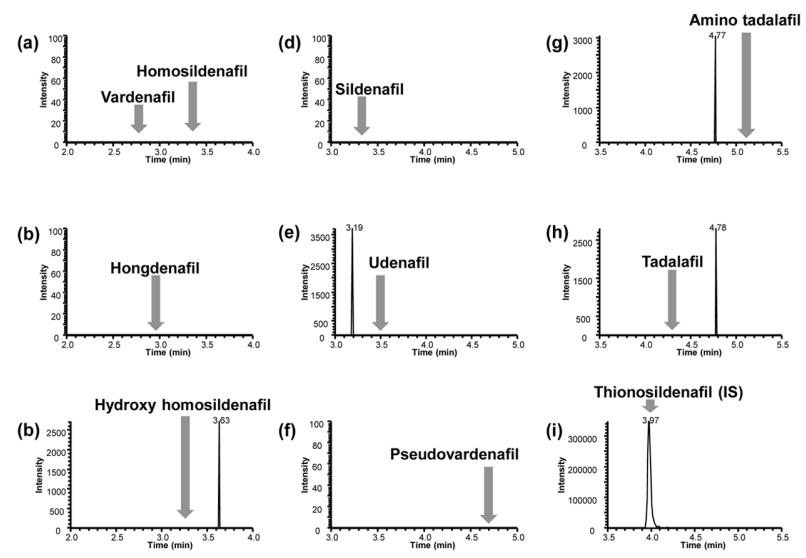

Figure 2. Representative chromatograms of blank sample for nine PDE-5 inhibitors and internal standard.
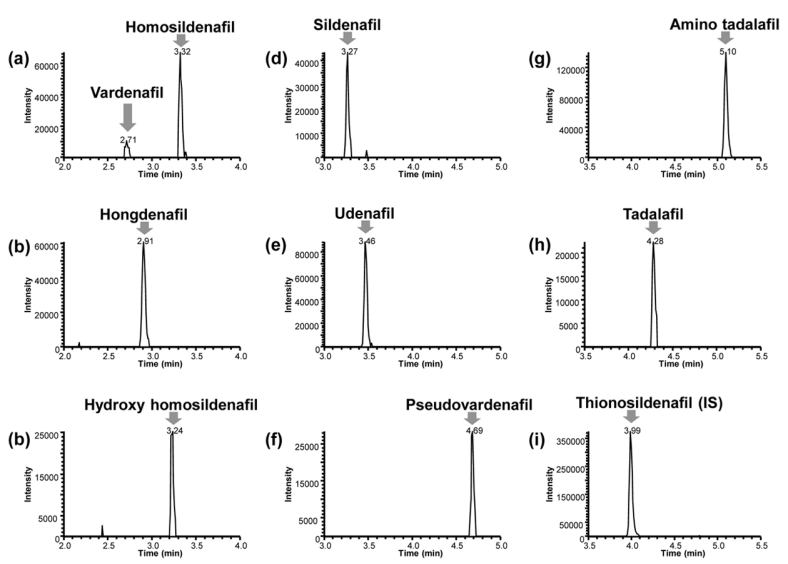

Figure 3. Representative chromatograms of the lowest calibration sample ( $40 \mu \mathrm{g} / \mathrm{g}$ ) for nine PDE-5 inhibitors and internal standard.
The use of reconstructed ion chromatograms (RICs) with very narrow mass tolerance windows enabled the discrimination of the target molecules from sample matrix and improved the selectivity of an LC-MS method.

Representative chromatograms of blank sample spiked with IS and the calibration sample at the lowest concen- tration are shown in Figure 2 and 3, respectively. No interfering peaks were observed near the retention time of all target molecules in the blank sample matrix. The signal to noise $(S / N)$ ratio of all analytes showed greater than 10 at the lowest concentration.

\section{Linearity}

Calibration standards of all nine target molecules were prepared by spiking appropriate amount of the standard solutions over the concentration range from 40 to $2000 \mu \mathrm{g} /$ g. The correlation coefficient $\left(r^{2}\right)$ of the calibration curve was obtained by linear regression. Acceptable linearity was

Table 2. Intra-day and inter-day validation

\begin{tabular}{|c|c|c|c|c|c|}
\hline \multirow[b]{2}{*}{ Compound } & \multirow{2}{*}{$\begin{array}{l}\text { Concentra- } \\
\text { tion }(\mu \mathrm{g} / \mathrm{g})\end{array}$} & \multicolumn{2}{|c|}{ Intra-day } & \multicolumn{2}{|c|}{ Inter-day } \\
\hline & & $\begin{array}{c}\text { Accu- } \\
\text { racy }(\%)\end{array}$ & $\mathrm{CV}(\%)$ & $\begin{array}{c}\text { Accu- } \\
\text { racy }(\%)\end{array}$ & CV (\%) \\
\hline \multirow{4}{*}{ Vardenafil } & 40 & 100 & 4.6 & 98 & 3.4 \\
\hline & 200 & 103 & 4.0 & 107 & 5.2 \\
\hline & 1000 & 102 & 2.9 & 100 & 8.3 \\
\hline & 40 & 103 & 5.1 & 101 & 4.9 \\
\hline \multirow[t]{2}{*}{ Homosildenafil } & 200 & 110 & 5.7 & 107 & 4.0 \\
\hline & 1000 & 102 & 2.0 & 98 & 5.7 \\
\hline \multirow{3}{*}{ Hongdenafil } & 40 & 91 & 1.2 & 99 & 7.5 \\
\hline & 200 & 95 & 7.4 & 95 & 4.8 \\
\hline & 1000 & 95 & 5.0 & 94 & 11.0 \\
\hline \multirow{3}{*}{$\begin{array}{c}\text { Hydroxy } \\
\text { Homosildenafil }\end{array}$} & 40 & 102 & 1.7 & 102 & 5.0 \\
\hline & 200 & 105 & 6.3 & 105 & 4.9 \\
\hline & 1000 & 100 & 1.7 & 97 & 4.7 \\
\hline \multirow{3}{*}{ Sildenafil } & 40 & 91 & 7.9 & 95 & 9.4 \\
\hline & 200 & 113 & 3.9 & 107 & 6.0 \\
\hline & 1000 & 106 & 1.0 & 101 & 7.9 \\
\hline \multirow{3}{*}{ Udenafil } & 40 & 99 & 3.7 & 99 & 3.8 \\
\hline & 200 & 109 & 5.5 & 108 & 3.8 \\
\hline & 1000 & 100 & 2.0 & 97 & 5.8 \\
\hline \multirow{3}{*}{$\begin{array}{c}\text { Pseudovard- } \\
\text { enafil }\end{array}$} & 40 & 105 & 2.5 & 98 & 6.4 \\
\hline & 200 & 104 & 3.5 & 110 & 4.6 \\
\hline & 1000 & 106 & 1.6 & 100 & 10.2 \\
\hline \multirow{3}{*}{$\begin{array}{l}\text { Amino } \\
\text { Tadalafil }\end{array}$} & 40 & 100 & 3.8 & 101 & 5.4 \\
\hline & 200 & 106 & 1.6 & 102 & 4.0 \\
\hline & 1000 & 102 & 1.9 & 100 & 2.4 \\
\hline \multirow{3}{*}{ Tadalafil } & 40 & 99 & 3.4 & 100 & 5.3 \\
\hline & 200 & 113 & 3.4 & 106 & 6.0 \\
\hline & 1000 & 106 & 0.4 & 97 & 7.4 \\
\hline
\end{tabular}


Table 3. Determination of PDE-5 inhibitors in dietary supplements

\begin{tabular}{|c|c|c|}
\hline \multirow[t]{2}{*}{ Supplements } & $\begin{array}{l}\text { Labeled substance } \\
\text { (concentration) }\end{array}$ & $\begin{array}{l}\text { Measured substance } \\
\text { (concentration) }\end{array}$ \\
\hline & Sildenafil (100 mg) & Sildenafil (240 mg) \\
\hline & Tadalafil (20 mg) & Sildenafil (60 mg) \\
\hline & Sildenafil (100 mg) & Sildenafil (300 mg) \\
\hline & $\begin{array}{l}\text { Schizandra \& balloon } \\
\text { flower (Unknown) }\end{array}$ & Sildenafil (70 mg) \\
\hline & Pine needles (Unknown) & Sildenafil (150 mg) \\
\hline & Kelp (Unknown) & Sildenafil (600 mg) \\
\hline & Glasswort (Unknown) & Sildenafil (400 mg) \\
\hline
\end{tabular}

observed for all substances $\left(r^{2}>0.99\right)$ and the average back-calculated concentration of full range did not exceed $\pm 15 \%$ of theoretical value (date not shown).

\section{Precision, accuracy and sensitivity}

To evaluate precision and accuracy, the intra-day and inter-day validations were performed by determining quality control samples at three concentrations levels (40, 200 and $1000 \mu \mathrm{g} / \mathrm{g})$. The intra-day and inter-day variation for nine PDE-5 inhibitors over the entire concentration ranges are presented in Table 2. The intra-day coefficients of variation were $0.4-7.9 \%$, and accuracies ranged $91-113 \%$, respectively. The inter-day coefficients of variation were 2.4$11.0 \%$, and accuracies ranged $94-110 \%$, respectively.

The lower limit of quantification (LOQ) was determined as the lowest concentration on the standard calibration curve which was measured with an accuracy of between $80 \%$ and $120 \%$ and a precision of less than $20 \%$. The current assay had the LOQ of $40 \mathrm{mg} / \mathrm{g}$ for all nine PDE-5 inhibitors.

\section{Determination of PDE-5 inhibitors in supplements}

The developed method was applied to the analysis of the seven illegal supplements including two tablets of unofficial Viagra and one of Cialis, and four pellets of natural products, supported from Supreme Prosecutors' Office (Table 3). The results revealed the serious in consistent doses of active pharmaceutical ingredients in illegal supplements, suggesting that the indiscriminate administration of these illegal supplements could run into danger.

\section{Conclusions}

A simple and rapid LC-HR/MS method has been developed and validated for the simultaneous determination of sildenafil and its derivatives in the illegal supplements. The present method was accurate and reproducible with $40 \mu \mathrm{g} / \mathrm{g}$ of the limit of quantification and useful for the analysis of the PDE-5 inhibitors in the illegal supplements.

\section{Acknowledgments}

This work was supported in part by an intramural grant from Korea Institute of Science and Technology and in part by a grant from National R\&D program of Ministry of Education, Science and Technology (MEST) and the National Research Foundation (NRF) of Korea.

\section{References}

1. Palit, V.; Eardley, I. Nat. Rev. Urol. 2010, 7, 603.

2. Reepmeyer, J. C.; Woodruff, J. T. J. Pharmaceut. Biomed. 2007, 44, 887.

3. Reepmeyer, J. C.; d'Avignon, D. A. J. Pharmaceut. Biomed. 2009, 49, 145.

4. Hou, P. L.; Zou, P.; Low, M. Y.; Chan, E. L.; Koh, H. L. Food Addit. Contam. 2006, 23, 870.

5. Balayssac, S.; Trefi, S.; Gilard, V.; Malet-Martino, M.; Martino, R.; Delsuc, M. A. J. Pharmaceut. Biomed. 2009, 50,602 .

6. Ahn, S.; Hong, J. Y.; Hong, M. K.; Jang, Y. P.; Oh, M. S.; Jung, J. H.; Hong, J. Rapid Commun. Mass Spectrom. 2009, 23, 3158 .

7. Liang, Q. L.; Qu, J.; Luo, G. A.; Wang, Y. M. J. Pharmaceut. Biomed. 2006, 40, 305.

8. Man, C. N.; Nor, N. M.; Lajis, R.; Harn, G. L. J. Chromatogr. A 2009, 1216, 8426.

9. Gryniewicz, C. M.; Reepmeyer, J. C.; Kauffman, J. F.; Buhse, L. F. J. Pharmaceut. Biomed. 2009, 49, 601.

10. Pyo, J.; Lee, H.; Park, Y.; Jo, J.; Park, Y.; Choe, S. Mass Spectrom. Lett. 2012, 3, 15.

11. Bogusz, M. J.; Hassan, H.; Ai-Enazi, E.; Ibrahim, Z.; AlTufail, M. J. Pharmaceut. Biomed. 2006, 41, 554.

12. Zhang, Y.; Huang, Z. Q.; Ding, L.; Yan, H. F.; Wang, M. L.; Zhu, S. H. J. Sep. Sci. 2010, 33, 2109.

13. Gratz, S. R.; Gamble, B. M.; Flurer, R. A. Rapid Commun. Mass Spectrom. 2006, 20, 2317.

14. van der Heeft, E.; Bolck, Y. J. C.; Beumer, B.; Nijrolder, A. W. J. M.; Stolker, A. A. M.; Nielen, M. W. F. J. Am. Soc. Mass Spectrom. 2009, 20, 451.

15. Holman, S. W.; Wright, P.; Langley, G. J. Anal. Chem. 2010, 82, 2347. 